\title{
Sikap, Aspirasi dan Kemampuan Wirausaha: Dimensi Utama Kinerja Kewirausahaan
}

\author{
P Eko Prasetyo \\ Fakultas Ekonomi, Universitas Negeri Semarang, Semarang, Indonesia \\ pekoprasetyo@mail.unnes.ac.id
}

\begin{abstract}
The purpose of this study is to analyze the effect of attitudes, aspirations and abilities of entrepreneurs towards the success of entrepreneurial performance. The main data source in this study used 2019 global entrepreneurship index data (GEINDEX) from 137 countries. The analytical method uses the path analysis model. The research results show there are three main factors that are most fundamental in achieving successful entrepreneurial performance, namely risk acceptance factors, internationalization aspirational factors, and the ability to absorb technology. In other words, the main basic capital to achieve successful entrepreneurial performance in the era of globalization: 1) must accept existing risks, 2) has the global thought aspirations (internationalization), and 3) have the capacity to absorb existing technology. However, the first key to success in achieving entrepreneurial performance is very much dependent on the strength of the aspirations or big dreams possessed by an entrepreneur.
\end{abstract}

Keywords: Entrepreneurial Abilities, Entrepreneurial Aspirations, Entrepreneurial Attitude, Performance of Entrepreneurial Success

\section{PENDAHULUAN}

Dimensi kinerja kewirausahaan sangat penting untuk mengindentifikasikan kesuksesan usaha secara berkelanjutan. Memiliki sikap, aspirasi dan kemampuan wirausaha yang baik dan elegan merupakan dimensi penting kesuksesan yang harus dimiliki oleh para wirausaha dalam setiap menjalankan kewirausahaannya. Memiliki aspirasi dan mimpi besar adalah modal awal untuk mencapai kesuksesan kinerja usaha kewirausahaan. Sementara, memiliki sikap mental wirausaha yang kuat merupakan kebutuhan utama dalam menjalankan aktivitas usaha kewirausahaannya. Selanjutnya, memiliki kemampuan mencari peluang usaha adalah modal utama untuk kesuksesan kinerja kewirausahaan.
Setiap kesuksesan memiliki berbagai dimensi ukurnya sendiri-sendiri. Dimensi kinerja kewirausahaan menjadi penting untuk mengidentifikasi kesuksesan usaha saat ini dan di masa depan (Fried \& Tauer, 2015). Ada beberapa pendorong aspirasi wirausaha dan motivasi wirausaha yang telah diselidiki menggunakan data tingkat negara dari Global Entrepreneurship Monitor (GEM) untuk tahun 2005 dan 2006 (Thurik \& Gelderen, 2008). Selanjutnya, kewirausahaan merupakan dimensi penting untuk kemajuan ekonomi suatau bangsa. Josep Alois Schumpeter, lebih dari seratus tahun lalu telah menunjukkan bahwa kewirausahaan sangat penting untuk dapat lebih memahami perkembangan ekonomi suatu negara. 
Dengan demikian, pokok masalah riset dalam makalah ini adalah untuk mencari jawaban mengapa kinerja kewirausahan menjadi semakin penting dilakukan. Efrata dan Maichal (2018) telah melakukan riset peran identitas wirausaha dan self-efficacy dalam model kinerja kewirausahaan. Hasil riset Efrata dan Maichal (2018) ini menunjukkan bahwa ada pola yang menghubungkan keberadaan panutan dan kinerja wirausaha. Tujuan umum riset ini untuk mengembangkan hasil riset tersebut, dan tujuan khususnya adalah lebih fokus untuk menjelaskan peran sikap, aspirasi dan kemampuan wirausaha terhadap peningkatan kesuksesan kinerja kewirausahaan.

\section{Sikap dan Kinerja Kewiruasahaan}

Sikap wirausaha yang dimaksud dalam hal ini merupakan sikap mental atau sifat utama atau watak dasar sebagai identitas atau ciri utama yang umumnya harus dimiliki oleh para wirausahawan di dalam menjalankan kehidupan usahanya. Dimensi ukur sikap wirausaha dapat dilihat dari beberapa hal seperti; mandiri, jujur, disiplin, realistis, kreatif, inovatif, komitmen, serta pintar memilih peluang, keberanian memulai usaha, menerima risiko, memiliki jaringan dan dukungan budaya. Dalam kegiatan sehari-harinya identitas seorang wirausaha dapat dicerminkan dari nilai-nilai sikap tersebut. Semakin tinggi dan baik sikap wirausaha tersebut, maka akan semakin baik kinerja dan niat kewirausahaan mereka.

Sikap wirausaha untuk meningkatkan kinerja kewirausahaan semakin memiliki posisi penting dalam kehidupan ekonomi, sosial, budaya masyarakat di dunia global yang terus berubah secara dinamis. Pada saat ini mulai terdapat peningkatan penekanan fokus penelitian kewirausahaan di seluruh dunia. Pada awalnya, niat individu untuk berperilaku wirausaha muncul karena para wirausahawan menganggap bahwa perilaku wirausaha dalam suatu organisasi sebagai pemaksimalan utilitas, dan dengan demikian membentuk motivasi untuk berperilaku wirausaha (Fitzsimmons \& Douglas, 2005). Sedangkan, hasil riset Ngan dan Khoi (2020), menunjukkan bahwa orientasi sikap wirausaha dipengaruhi oleh dua komponen utama yaitu; inovasi dan pengendalian pribadi.

Hasil riset Abun et al. (2018), menemukan ada korelasi positif yang signifikan antara sikap kewirausahaan dan niat siswa. Hasil riset tersebut menjelaskan secara keseluruhan sikap kewirausahan siswa yang tinggi dan niat kewirausahaan mereka juga tinggi. Selain itu, hasil riset Ali et al. (2013) yang telah mengeksplorasi sikap kewirausahaan di kalangan pengusaha potensial di Pakistan menjelaskan secara keseluruhan ada perbedaan signifikan antara sikap negatif dan positif, serta menegaskan bahwa mayoritas sampel menunjukkan sikap positif terhadap kewirausahaan.

Selanjutnya, pokok masalah riset Choe et al. (2013), bertujuan untuk lebih memahami bagaimana sikap kewirausahaan dapat mempengaruhi kinerja UKM di Malaysia. Hasil penelitian Choe et al. (2013), menunjukkan bahwa kelima dimensi sikap kewirausahaan yakni; (achievement, selfesteem, personal control, innovation dan opportunity recognition) berhubungan positif dengan kinerja perusahaan. Hasil riset terbaru (Prasetyo \& Siswantari, 2020d) bahwa kemampuan kinerja kewirausahaan menyerap teknologi baru yang inovatif serta memiliki sikap dan aspirasi yang baik dalam berkompetisi merupakan modal dasar utama sebagai upaya mengembangkan budaya kewirausahaan yang baik untuk menghadapi setiap tantangan yang besar dan mendorong kinerja global.

\section{Aspirasi dan Kinerja Kewirausahaan}

Aspirasi wirausaha dalam riset ini dimaknai sebagai suatu niat baik, atau keinginan yang kuat, harapan bisa lebih baik lagi, sebuah mimpi besar, suatu cita-cita atau ambisi kesuksesan seorang wirausaha dalam mencapai tujuan kinerja kewirausahaannya. Dalam riset ini, dimensi ukur aspirasi tersebut dapat dilihat dari berbagai indikator dalam pencapaian niat baik seperti; proses inovasi, produk hasil inovasi, produktivitas tinggi, pertumbuhan tinggi, market share yang luas, 
serta resiko yang minim dan terkendali. Hasil riset Prasetyo (2020a, 2019a) telah menjelaskan bahwa sebagian besar para pelaku usaha kewirausahaan UMKM memiliki staregi "tuna satak bathi sanak" sebagai aspirasi strategi bersaing atau "bertahan" dalam kinerja usahanya.

Dalam hal ini ambisi sebagai aspirasi mencapai kesuksesan kewirausahaan berbeda dengan kewirausahaan yang ambisius. Untuk mencapai kesuksesan kinerja kewiraausahaan yang baik, ambisi saja tidaklah cukup. Tetapi, "terlalu ambisi" (ambisius) adalah tidak baik dan tidak pernah dapat mencapai tujuan kesuksesan kinerja kewirausahaan yang baik (Stam et al., 2012). Sebelumnya, Stam et al. (2010) telah melakukan penelitian untuk menguji kewirausahaan yang ambisius dengan diggunakan data GEM dan indiktor Total Entrepreneurrial Activity (TEA). Hasil riset menjelaskan; efek positif keseluruhan ambisi kewirausahaan pada pertumbuhan ekonomi makro tidak hilang. Namun, berbeda dengan kewirausahaan yang ambisius yang baru lahir dan muda. Perusahaan dengan pertumbuhan tinggi yang lebih ambisius, tampaknya tidak berkontribusi terhadap pertumbuhan ekonomi makro (Stam et al., 2010).

Di sisi lain, hasil riset Herman et al (2012) menegaskan bahwa pengusaha yang ambisius mungkin merupakan populasi yang menarik bagi komunitas penelitian serta bagi para pembuat kebijakan dan praktisi lainnya. Hasil riset mereka, menunjukkan bahwa pengusaha yang ambisius memiliki dampak spesifik terhadap ekonomi dan berkontribusi pada kualitas kegiatan kewirausahaan. Secara konseptual, mengungkapkan bahwa tidak ada konsensus terkait dengan operasionalisasi kewirausahaan yang ambisius dan ambisi pertumbuhan secara umum (Herman et al., 2012). Selanjutnya, hasil riset Herman et al. (2012) telah mengidentifikasikan jalur yang menjanjikan untuk penelitian di masa depan dan mengusulkan konsep proses proyeksi tersebut untuk lebih memperjelas antara sikap pertumbuhan, niat pertumbuhan dan harapan pertumbuhan.

\section{Kemampuan dan Kinerja Kewirausahaan}

Secara umum, kemampuan wirausaha (entrepreneurial abilities) maknanya sangat luas. Namun kaitanya dengan riset ini, makna kemampuan wirausaha cenderung diukur dari dimensi kemampuan; memperoleh peluang baru, penyerapan teknologi, berkompetisi, berinovasi, manajerial risiko, human capital, dan Need for Achiement (N-Ach). Dalam kaitan ini, kemampuan human capital dan social capital wirausaha sebagai diterminan penting utama dalam mendorong peningkatan pertumbuhan ekonomi dan daya saing usaha berkelanjutan (Prasetyo, 2020b, 2020c, \& 2019b). Acs et al. (2012) membangun model riset human capital sebagai sumber utama daya serap kewirausahaan. Hasil risetnya menjelaskan bahwa human capital sangat penting untuk usaha kewirausahaan, karena mempengaruhi aktivitas kewirausahaan. Temuan kuncinya adalah terletak pada hubungan kuat antara toleransi dan kewirausahaan (Acs et al., 2019; 2012).

Kemampuan technology absorption, opportunity startup, human capital, competition, dan inovasi sebagian besar dipandang sebagai sumber penting untuk menghasilkan kinerja keunggulan kompetitif kewirausahaan yang berkelanjutan (Prasetyo \& Siswantari, 2020d; Mao et al., 2020; Atiase et al., 2020; Khouroh et al., 2020). Hasil riset Mao et al. (2020) menunjukkan bahwa inovasi dan penyerapan teknologi sangat menguntungkan masyarakat melalui peningkatkan komunikasi dan kinerja tingkat produktivitas melalui supply chain. Khouroh et al (2020) menunjukan bahwa fokus inovasi sebagai bagian dari kemampuan entrepreneurial marketing berkontribusi dalam meningkatkan keunggulan bersaing berkelanjutan. Sedangkan, menurut penelitian Atiase et al. (2020), variabel penyerapan teknologi dan indek human capital menjadi variabel outcome dan penjelas terpenting untuk pertumbuhan ekonomi dan kinerja kewirausahaan. Selanjutnya, hasil riset Prasetyo dan Siswantari (2020d) menegaskan bahwa technology absorption telah menjadi diterminan utama dalam peningkatan kinerja kewirausahaan global. 
Kontribusi teoritis utama dari konsep kemampuan wirausaha dalam riset ini adalah bahwa kemampuan human capital dan penyerapan teknologi wirausaha UMKM terbukti mampu mendorong peningkatan kinerja bisnis kewirausahan semakin lebih baik. Sajilan et al. (2016) telah melakukan penelitian keterkaitan antara kompetensi kewirausahaan UMKM dengan kinerja bisnis. Hasil riset tersebut menunjukkan bahwa kinerja bisnis UMKM akan sangat bergantung pada kompetensi faktor internal dan eksternal, termasuk langkah-langkah keuangan dan nonkeuangan (Sajilan et al., 2016).

Selanjutnya, keterampilan penting dan sangat diperlukan untuk meningkatkan kinerja operasi UKM yang lebih baik di wilayah Kota Mumbai (Nehete et al., 2016). Sedangkan, studi Eton et al. (2017) telah menggunakan variabel peran keterampilan kewirausahaan dalam kinerja UMKM di Uganda, menemukan bahwa keterampilan kewirausahaan tidak dapat menjelaskan jumlah total variasi dalam kinerja UKM karena hanya berkontribusi $32,5 \%$ dari tingkat kinerja pada tingkat distrik Nebbi di Uganda. Sedangkan, hasil riset Prasetyo dan Dzaki (2020e) lebih menegaskan bahwa peran kinerja kelembagaan dan pengembangan produk baru melalui value chain ikut mendorong kinerja keunggulan daya saing kewirausahaan di Indonesia.

\section{METODE}

\section{Data dan Sumber Data}

Kemajuan teknologi menyebabkan sejumlah besar data yang telah dikumpulkan, dikompilasi, serta diarsipkan, dan yang sekarang mudah diakses untuk penelitian. Akibatnya, memanfaatkan data yang ada untuk penelitian menjadi lebih umum (Johnston, 2014, Martins \& da-Cunha, 2018). Dalam penelitian ini digunakan sumber data sekunder dari indeks kewirausahaan global (GEINDEX) The Global Entrepreneurship Index, GEDI \& RIERC (Acs et al., 2019). Di mana GEINDEX ini menangkap fitur kontekstual kewirausahaan dengan berfokus pada sikap kewirausahaan, kemampuan wirausaha dan aspirasi wirausaha.
Selanjutnya, dukungan data ini dan kontribusinya terhadap proses pembentukan kinerja bisnis didukung oleh tiga dekade penelitian kewirausahaan di sejumlah 137 negara yang digunakan sebagai sampel dalam riset ini. Konstruksi indeks mengintegrasikan 31 variabel, 17 dari GEM, dan 14 dari sumber data lain, kemudian menjadi 14 pilar, tiga sub indeks dan 'indeks super'. Dalam riset ini digunakan tiga data sub indek yakni; sikap kewirausahaan, kemampuan wirausaha dan aspirasi wirausaha dan satu indek besar GEI sebagai dimensi kinerja kewirausahaan (KK).

Dalam riset ini, untuk variabel Sikap Wirausaha (SW) diukur dengan dimensi nilai indek; Opportunity Perception (OP), Startup Skill (SS), Networking (Nw), Risk Acceptance (RA) dan Culture Support (SC). Sementara itu, untuk variabel aspirasi wirausaha (AW) diukur dengan dimensi indek; Process Inovation (PsI), Product Innovation (PI), High Growth (HG), Risk Capital (RC), dan Internationalization (In). Sedangkan, untuk variabel Kemampuan Wirausaha (KW) diukur dengan dimensi; Opportunity Startup (OP), Technology Absorption (TA), Human Capital (HC), dan Competition (Cpt). Selanjutnya, khusus untuk variabel kinerja kewirausahaan digunakan dimensi data indek besar GEI.

Selanjutnya, dalam makalah ini, pilarpilar tersebut adalah sebagai blok bangunan dasar dari sub indeks variabel pokok yang digunakan yakni; aspirasi wirausaha (ASP) dan Kemampuan kewirausahaan (ABT). Nilai sub indeks untuk setiap negara manapun adalah rerata aritmatika dari pilar tersebut, sehingga formulasinya dapat diukur sebagai berikut (Acs, et.al, 2019).

$$
\begin{aligned}
A S P_{i} & =100 \sum_{j=10}^{14} h j \ldots \ldots \ldots . . . \\
A B T_{i} & =100 \sum_{j=6}^{9} h j \ldots \ldots \ldots .(2)
\end{aligned}
$$

Di mana $h \_i i$ dan $h \_j j$ adalah nilai indek pilar-j yang dimodifikasikan dan pascapeneliti di negara i. Sedangkan, $i=1,2,3 \ldots n$ adalah jumlah negara dan $\mathrm{j}=1,2, \ldots 14$ adalah jumlah pilar. Selanjutnya, nilai maksimum 
dari sub-indeks adalah 100 dan potensi minimum adalah 0 , keduanya mencerminkan posisi relatif suatu negara dalam sub-indeks tertentu. Artinya daya serap semakin besar mendekati satu artinya kinerja kewirausahaan semakin baik dan semakin kecil mendekatai nol semakin lemah.

\section{Model Analisis Penelitian}

Riset ini menegaskan bahwa analisis data sekunder adalah metode yang layak untuk digunakan dalam proses penyelidikan yang tetap sistematis dengan memanfaatkan analisis data sekunder yang bersumber dari (GEINDEX), indeks kewirausahaan global (Acs et al., 2019). Dalam riset ini digunakan metode path analysis untuk menjelaskan pengaruh langsung, pengaruh tidak langsung dan pengaruh total dari peran variabel; sikap wirausaha (SW), aspirasi wirausaha (AW) dan kemampuan wirausaha $(\mathrm{KW})$ terhadap kinerja kewirausahaan (KK).

Landasan konsep penggunaan analisis ini didasarkan pada dasar pemikiran bahwa kemampuan wirausaha (KW) dapat terbentuk karena seorang wirausahawan telah memiliki berbagai aspirasi bisnis dan sikap wirausaha yang kuat dan baik untuk menjalankan usaha kewirausahannya. Selanjutnya, dari faktor dasar sikap wirausaha (SW), dan apirasi wirausaha (AW) yang dimiliki bersama dengan faktor kemampuan wirausaha (KW) akan semakin kuat mendorong aktivitas kinerja kewirausahaan mejadi semakin baik. Secara umum, dimensi kinerja kewirausahaan dalam hal ini dapat diukur dalam dimensi pertumbuhan dan kesuksesan usahanya.

Sebelum model path analysis digunakan, agar lebih mudah dipahami, terlebih dahulu dapat dirumuskan bentuk persamaan fungsi matematika dan bentuk persamaan struktural yang digunakan. Dalam riset ini dapat disusun bentuk persamaan fungsi matematika dan bentuk persamaan struktural sebagai berikut.

$$
\begin{aligned}
& \mathrm{SW}=\mathrm{f}(\mathrm{OP}, \mathrm{SS}, \mathrm{RA}, \mathrm{Nw}, \mathrm{CS}) \\
& \mathrm{AW}=\mathrm{f}(\mathrm{PsI}, \mathrm{PI}, \mathrm{HG}, \mathrm{It}, \mathrm{RC}) \ldots \\
& \mathrm{KW}=\mathrm{f}(\mathrm{OS}, \mathrm{TA}, \mathrm{HC}, \mathrm{Cpt}) \ldots \ldots \\
& \mathrm{KW}=\mathrm{f}(\mathrm{SW}, \mathrm{AW}) \ldots \ldots \ldots \ldots \ldots \\
& \mathrm{KK}=\mathrm{f}(\mathrm{SW}, \mathrm{AW}, \mathrm{KW}) \ldots \ldots \ldots
\end{aligned}
$$

Persamaan satu sampai dengan persamaan lima adalah model bentuk persamaan dasar fungsi matematika yang digunakan dalam bentuk analisis regresi linier model OLS. Selanjutnya, berdasarkan konsep dasar pada pemikiran penelitian di atas, maka bentuk dasar persamaan struktural untuk model path analysis-nya dari persamaan 6 dan 7 menjadi sebagai berikut pada persaman 8 dan 9 .

$\mathrm{KW}=\rho_{\mathrm{KW}} \cdot \mathrm{SW}+\rho_{K W} \cdot \mathrm{AW}+\varepsilon_{1}$

$\mathrm{KK}=\rho_{\mathrm{KK}} \cdot \mathrm{SW}+\rho_{\mathrm{KK}} \cdot \mathrm{AW}+\rho_{K K} \cdot \mathrm{KW}+\varepsilon_{2}$

Berdasarkan model bentuk persamaan 6 dan 7 selanjutnya dapat dibuat bentuk diagram jalur model path analysis sebagai berikut.

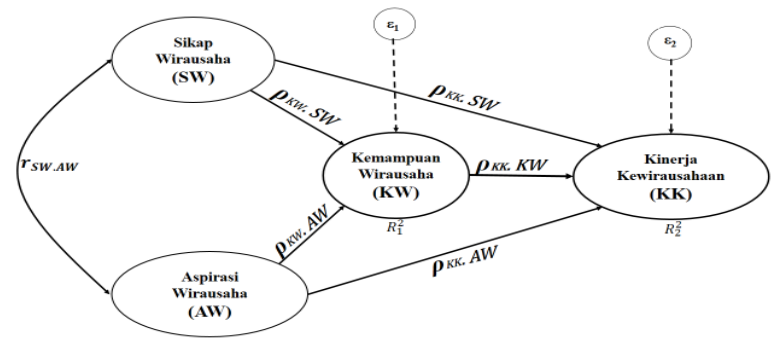

Gambar 1. Model Diagram Path Analysis

\begin{tabular}{|c|c|c|c|c|c|}
\hline \multirow[t]{2}{*}{$\begin{array}{c}\text { Model } \\
\text { Persamaan }\end{array}$} & \multicolumn{2}{|c|}{$\begin{array}{c}\text { Unstandardized } \\
\text { Coefficients }\end{array}$} & \multirow{2}{*}{$\begin{array}{c}\begin{array}{c}\text { Standardized } \\
\text { Coefficients }\end{array} \\
\text { Beta }\end{array}$} & \multirow[t]{2}{*}{ t-Stk. } & \multirow[t]{2}{*}{ Sig. } \\
\hline & $\mathrm{B}$ & Std. Error & & & \\
\hline (Constant) & 0,017 & 0,504 & & 0,033 & 0,974 \\
\hline OP & 16,911 & 1,359 & 0,181 & 12,441 & 0,000 \\
\hline SS & 17,153 & 0,833 & 79 & 20,595 & 0,000 \\
\hline RA & 20,414 & 0,982 & 28 & 20,790 & 0,000 \\
\hline $\mathrm{Nw}$ & 15,756 & 1,103 & & 14,283 & 0,000 \\
\hline $\mathrm{CS}$ & 19,617 & 1,395 & 0,247 & 14,060 & 0,000 \\
\hline \multicolumn{6}{|c|}{ Model-1: SW = 0,181OP + 0,279SS + 0,328RA+0,195Nw+0,247CS +ei } \\
\hline (Constant) & 1,380 & 0,517 & & 2,669 & 0,009 \\
\hline PI & 16,916 & 1,517 & 0,210 & 11,148 & 0,000 \\
\hline PsI & 18,247 & 1,529 & 0,240 & 11,934 & 0,000 \\
\hline HG & 13,916 & 1,627 & 0,171 & 8,554 & 0,000 \\
\hline It & 18,287 & 1,180 & 0,286 & 15,492 & 0,000 \\
\hline $\mathrm{RC}$ & 17,905 & 1,672 & 0,246 & 10,709 & 0,000 \\
\hline \multicolumn{6}{|c|}{ Model-2:AW=0,210PI +0,240PsI +0,171HG +0,286It +0,246RC + $\mathrm{e}_{2}$} \\
\hline (Constant) & 1,010 & 0,443 & & 2,283 & 0,024 \\
\hline OS & 21,470 & 1,675 & 0,290 & 12,818 & 0,000 \\
\hline TA & 24,531 & 1,265 & 0,351 & 19,390 & 0,000 \\
\hline $\mathrm{HC}$ & 19,078 & 1,143 & 0,244 & 16,685 & 0,000 \\
\hline $\mathrm{Cpt}$ & 22,430 & 1,800 & 0,235 & 12,464 & 0,000 \\
\hline \multicolumn{6}{|c|}{ Model-3:KW $=0,290 \mathrm{OS}+0,351 \mathrm{TA}+0,244 \mathrm{HC}+0,235 \mathrm{Cpt}+\mathrm{e}_{3}$} \\
\hline
\end{tabular}
Peningkatan Kinerja Kewirausahaan

\section{HASIL DAN PEMBAHASAN}

Tabel 1. Hasil Analisis Regresi Path Analysis Model Standardized

Sumber data: GEI Indek, 2019 (diolah)

Agar lebih mudah dipahami dengan baik dan cepat, maka sistematika penyajian hasil dan pembahasan digabung menjadi satu bagian. Diskusi dan penjelasan yang ada didasarkan kepada hasil dan riset terhahulu dan dasar teori yang diacu. Tujuannya adalah 
agar analisis lebih baik, kritis dan lebih mendalam

Berdasarkan hasil analisis Tabel 1, nampak bahwa faktor dominan terbesar yang mempengaruhi sikap wirausaha adalah sikap wirausaha dalam menerima resiko (risk acceptance) yakni sebesar 32,8\%. Sedangkan, faktor terbesar yang dapat mempengaruhi aspirasi para wirausahawan adalah dari dimensi memiliki wawasan global jauh ke depan (internazionalization) yakni sebesar $28,6 \%$. Selanjutnya, yang paling besar mempengaruhi kemampuan wirausaha adalah faktor kemampuan dalam menyerap dan mengaplikasikan nilai-nilai teknologi berkaitan dengan kewirausahaan secara global (technology absorption) yakni sebesar $35,1 \%$. Hasil riset ini mendukung riset sebelumnya yang telah dilakukan oleh (Atiase et al., 2020; Mao et al., 2020 dan Prasetyo \& Siswantari, 2020d) seperti yang telah dijelaskan pada sub pendahuluan di atas, bahwa technology absorption menjadi diterminan utama.

Dengan demikian, analisis kritis yang dapat lihat adalah bahwa secara sederhana modal dasar sebagai seorang wirausahawan yang akan sukses secara global minimal harus memiliki sikap menerima dan mengelola resiko yang ada dengan baik, karena bisnis tentu penuh resiko. Tetapi, resiko itu tidak untuk dihindari melainkan dihadapi dan dianggap sebagai peluang dan tantangan. Cara menghadapi resiko tersebut adalah dengan cara memperbesar atau meningkatkan kapasitas, terutama kapasitas penyerapan dan penguasaan teknologi dan inovasi.

Seorang wirausahawan harus selalu memiliki sikap positif untuk lebih dahulu fokus kepada solusi yang dapat diambil bukan fokus pada masalah. Selain itu, seorang wirausahawan sukses harus memiliki aspirasi dasar atau wawasan global jauh ke depan (internationalization). Artinya, adalah walaupun seorang wirausaha bertindak lokal dengan memanfaaatkan kearifan lokal, tetapi harus tetap berpikir global. Selanjutnya, seorang wirausahawan yang sukses harus memiliki kapasitas kemampuan dasar dalam menyerap dan mengaplikasikan dengan baik perkembangan teknologi di era globalisasi saat ini atau di era revolusi industri 4.0.

Berdasarkan hasil riset pada Tabel 1, sebenarnya banyak faktor yang positif dan signifikan yang dapat mempengaruhi; sikap wirausahawan, aspirasi wirausaha dan kemampuan wirausaha. Selanjutnya berbagai faktor tersebut menjadi sangat menentukan kesuksesan aktivitas kinerja kewirausahaan yang dimiliki. Dengan kata lain, ada tiga kata kunci utama yang dapat dijadikan sebagai modal dasar paling fundamental untuk dapat meningkatkan aktivitas kesuksesan kinerja kewirausahaan. Seorang wirausahawan harus memiliki sikap mental untuk menerima resiko yang ada, serta memiliki cara berpikir global jauh ke depan (internazionalization) dan harus memiliki kemampuan menyerap serta menerapkan perkembangan nilai-nilai teknologi di era digitalis saat ini dan ke depan dalam kehidupan nyata. Artinya, hasil riset ini ikut mendukung penyelaraskan literatur studi kewirausahaan internasional dengan kewirausahaan arus utama yang telah dilakukan oleh (Ruzzier et al., 2020).

Untuk menuju ke pencapaian kinerja kewirausahawan yang sukses dalam era globalisasi, seorang wirausahawan tidak cukup hanya mampu membuat produk yang dihasilkan secara kreatif, efisien dan efektif saja, tetapi juga harus produktif, inovatif dan adaptif. Tanpa kapasitas kemampuan inovatif, produktif dan adaptif, maka akan semakin sulit kinerja kesuksesan kewirausahaannya akan dicapai. Selanjutnya, jika kinerja kewirausahaan tidak baik di negara para wirausahawan tersebut, maka negara dan bangsa yang bersangkutan akan semakin sulit berkembang di era global.

Berdasarkan hasil penelitian pada Tabel 2 dalam model 6, nampak semakin jelas bahwa pengaruh faktor aspirasi wirausaha lebih besar dibanding pengaruh faktor sikap wirausaha terhadap kemampuan usaha kewirausahan. Faktor aspirasi wirausaha mampu memberikan kontribusi positif dan signifikan sebesar $59,0 \%$ terhadap kemampuan wirausaha. Sedangkan, faktor sikap wirausaha memberikan kontribusi positif dan signifikan sebesar 40,2\% terhadap 
kemampuan wirausaha. Artinya, untuk menjadi seorang wirausaha agar memiliki kemampuan terlebih dahulu harus memiliki aspirasi atau cita-cita atau visi yang baik terlebih dahulu.

Selanjutnya jika di lihat dalam model 7 pada Tabel 2, nampak semakin meyakinkan bahwa faktor aspirasi masih memberikan kontribusi yang dominan di banding faktor sikap dan kemampuan wirausaha terhadap kesuksesan kinerja kewirausahaan. Faktor aspirasi wirausaha secara positif dan signifikan mampu memberikan kontribusi sebesar 36,5\% terhadap kesuksesan kinerja kewirausahaan. Sementara itu, faktor sikap dan kemampuan wirausaha masing-masing hanya memberikan kontribusi secara positif dan signifikan sebesar 32,1\% dan 35,0\%. Berdasarkan hasil riset pada Tabel 2 dan Tabel 3, dapat dinyatakan bahwa aspirasi merupakan diterminan utama dan pertama uantuk dapat meraih kesuksesan kinerja kewirausahaan secara global.

Tabel 2. Hasil Regresi Path Analysis Kinerja Kewirausahaan

\begin{tabular}{|c|c|c|c|c|c|c|}
\hline & \multirow[t]{2}{*}{ Model } & \multicolumn{2}{|c|}{$\begin{array}{l}\text { Unstandardized } \\
\text { Coefficients }\end{array}$} & \multirow{2}{*}{$\begin{array}{c}\text { Standardized } \\
\text { Coefficients } \\
\text { Beta }\end{array}$} & \multirow[t]{2}{*}{ t-stc } & \multirow[t]{2}{*}{ Sig. } \\
\hline & & B & Std. Error & & & \\
\hline \multirow{3}{*}{6} & (Constant) & $-0,270$ & 1,081 & & $-0,249$ & 0,804 \\
\hline & SW & 0,439 & 0,053 & 0,402 & 8,282 & 0,000 \\
\hline & AW & 0,565 & 0,047 & 0,590 & 12,146 & 0,000 \\
\hline \multicolumn{7}{|c|}{$\mathrm{KW}=0,402 \mathrm{SW}+0,590 \mathrm{AW}+\varepsilon_{4}$} \\
\hline \multirow{4}{*}{7} & (Constant) & $-0,006$ & 0,006 & & $-0,921$ & 0,359 \\
\hline & SW & 0,334 & 0,000 & 0,321 & 925,036 & 0,000 \\
\hline & $\mathrm{AW}$ & 0,333 & 0,000 & 0,365 & 893,090 & 0,000 \\
\hline & KW & 0,333 & 0,000 & 0,350 & 696,513 & 0,000 \\
\hline \multicolumn{7}{|c|}{$\mathrm{KK}=0,321 \mathrm{SW}+0,365 \mathrm{AW}+0,350 \mathrm{KW}+\varepsilon_{5}$} \\
\hline
\end{tabular}

Sumber: data GEINDEX, 2019 (diolah).

Berdasarkan hasil penelitian pada Tabel 1 dan Tabel 2, analisis kritis yang menarik adalah bahwa untuk menjadi seorang wirausahawan yang sukses, modal utama dan pertama yang harus dimiliki adalah sebuah aspirasi atau "mimpi besar" untuk hidup sukses mulia. Hasil riset ini nampaknya mampu memperkuat pernyataan yang sering disampaikan oleh seorang motivator sukses Indonesia bernama Jamil Azzaini, dengan apa yang dikenal dengan "Proposal Hidup untuk Sukses Mulia yang diawali dari mimpinya".

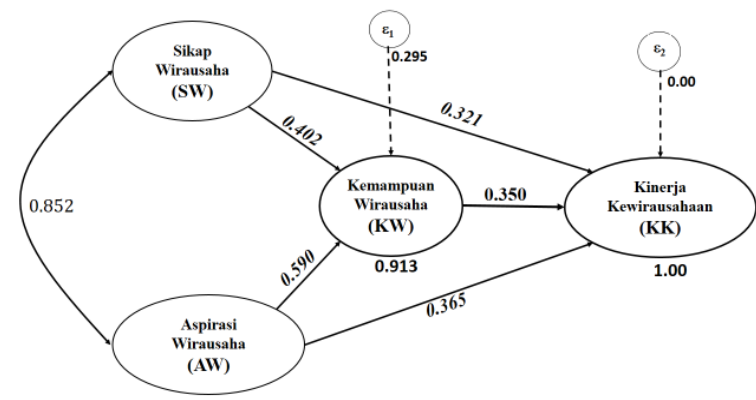

Gambar 2. Hasil Model Path Analysis Bentuk Rekursif Dalam Meningkatkan Kinerja Kewirausahaan

Pernyataan seorang motivator terkenal dan sukses Jamil Azzaini tersebut, secara akademik global terbukti benar berdasarkan hasil analisis pada Tabel 2 . Orisinalitas dan catatan kritisnya adalah, setelah memiliki aspirasi dan mimpi hidup sukses mulia dan memiliki sikap yang ramah terhadap resiko, maka para wirausahawan kemudian baru bisa memiliki kemampuan usaha untuk dapat menjadi seorang wirausahawan sukses yang selanjutnya akan mampu mendorong aktifitas kesuksesan hidup kinerja kewirausahannya.

Model pemikiran kritis ini nampak semakin jelas dilihat pada Gambar 2 dan Tabel 3. Dengan demikian, orisinalitas dan novelty hasil riset ini menegaskan bahwa semakin besar aspirasi "mimpi", maka akan semakin siap seorang untuk memiliki sikap mengelola risiko dengan baik, serta memiliki kapasitas menyerap teknologi dengan baik, sehingga akan semakin mendorong keunggulan kinerja daya saing kinerja kewirausahaan secara berkelanjutan. Hasil riset ini secara teori ikut memperkaya literature hasil riset sebelumnya yang telah dilakukan oleh (Thurik et al., 2008; Vamvaka et al., 2020). Aspirasi kewirausahaan dan motivasi, sebagai penggerak kewirausahaan (Thurik et al., 2008). Sedangkan, sikap dan aspirasi wirausahawan sebagai kontrol perilaku niat kewirausahan (Vamvaka et al., 2020).

Karena, dengan semakin besar aspirasi dan "mimpi besarnya" yang dimiliki, maka semakin siap dalam memiliki sikap mental untuk menerima resiko yang ada 
dalam usahanya, serta mampu mengelolanya dengan baik untuk memperoleh nilai keuntungan. Kemudian, dengan semakin besar memiliki kapasitas menyerap perkembangan teknologi yang ada, maka selanjutnya menjadi semakin lebih mudah untuk mencapai kesuksesan kinerja kewirausahaan di era globalisasi dan era revolusi industri saat ini dan ke depan secara berkelanjutan.

Tabel 3. Hasil Pengaruh Langsung, Tidak Langsung Dan Total Terhadap Kesuksesan Kinerja Kewirausahaan

\begin{tabular}{ccccccc}
\hline \multirow{2}{*}{ Variabel } & $\begin{array}{c}\text { Pengaruh } \\
\text { langsung }\end{array}$ & \multicolumn{2}{c}{ Pengaruh tidak langsung } & Sub & Pengaruh \\
& AW & SW & KW & total & Total \\
\hline AW & 0,133 & & 0,099 & 0,075 & 0,174 & 0,307 \\
SW & 0,103 & 0,099 & & 0,045 & 0,144 & 0,247 \\
KW & 0,123 & 0,075 & 0,045 & & 0,120 & 0,243 \\
Total & 0,359 & & & & 0,438 & 0,797 \\
\hline
\end{tabular}

Sumber: data GEINDEX, 2019 (diolah)

Berdasarkan hasil riset pada Tabel 3, semakin nampak jelas dan meyakinkan bahwa faktor aspirasi wirausaha mampu memberikan pengaruh terbesar utama dan pertama baik secara langsung, tidak langsung serta pengaruh totalnya. Secara berurutan, besarnya pengaruh total terbesar terhadap kesuksesan kinerja kewirausahaan adalah diberikan oleh faktor aspirasi wirausaha, $30,7 \%$, dari faktor sikap wirausaha sebesar $24,7 \%$ dan kemampuan wirausaha sebesar $24,3 \%$. Jika dilihat secara lebih spesifik, nampaknya pengaruh secara tidak langsung lebih besar diberikan dari faktor aspirasi dan sikap wirausaha terhadap kinerja kesuksesan kewirausahaan. Sedangkan faktor kemampuan wirusahawan hanya sedikit lebih besar memberikan pengaruh secara langsung daripada pengaruh tidak langsung terhadap kinerja kewirausahaan.

Karena faktor pengaruh tidak langsung dari aspirasi dan sikap wirausaha terhadap kinerja kewirausahaan lebih besar, maka fenomena ini dianggap masih membutuhkan faktor pendukung utama sebagai pendorong untuk menuju tercapainya kesuksesan kinerja kewirausahaan. Fenomena menarik yang perlu dicermati dalam hal ini adalah, kehebatan faktor aspirasi dan kehandalan sikap wirausahawan harus tetap dapat dijembatani dengan adanya faktor kemampuan wirausaha agar lebih mampu menuju kesuksesan kinerja kewirausahawan secara berkelanjutan.

\section{Kesimpulan}

Secara akademik semakin meyakinkan bahwa; semakin besar aspirasi dan "mimpi besarnya" maka semakin siap dalam memilih sikap untuk menerima resiko yang ada dan mampu mengelolanya dengan baik, sehingga semakin baik memiliki kapasitas kemampuan meyerap perkembangan teknologi yang ada, dan selanjutnya menjadi semakin mudah untuk dapat mencapai kesuksesan kinerja kewirausahaan di era revolusi industri saat ini dan ke depan secara berkelanjutan. Secara akademik, terdapat pengaruh yang positif dan signifikan baik secara langsung, secara tidak langsung dan pengaruh total, antara sikap, aspirasi dan kemampuan wirausaha terhadap kesuksesan kinerja kiwirausahaan. Namun demikian, kunci sukses untuk dapat tercapainya kinerja kewirausahaan yang terbaik adalah sangat tergantung dari kekuatan aspirasi atau mimpi besar yang dimiliki oleh seorang wirausaha.

Berdasarkan model path analysis dapat disimpulkan bahwa faktor aspirasi wirausaha baik secara langsung, tidak langsung dan totalnya telah mampu memberikan kontribusi terbesar utama dan pertama terhadap kesuksesan kinerja kewirausahaan. Semakin baik aspirasi yang dimiliki wirausaha dan semakin kuat sikap mental wirausaha, maka akan semakin besar kapasitas kemampuan wirausaha dalam upaya mencapai kesuksesan kinerja kewirausahaan di era globalisasi.

Implikasi dan rekomendasi yang dapat diberikan adalah sebagai wirausahawan yang sukses, tidak harus selalu bertindak global, tetapi harus tetap berpikir global, walaupn hanya baru dapat bertindak lokal dengan memanfaatkan peluang yang ada berdasarkan kearifan lokal. Selain itu, harus memiliki kesadaran diri untuk terus-menerus selalu membangun sikap positif dan meningkatkan kapasitas diri secara bijaksana, agar mampu 
menyerap nilai-nilai teknologi inovasi dan mampu mengelola risiko yang terjadi agar menjadi solusi untuk meraih banyak rizki.

\section{Acknowledgement}

Terima kasih disampaikan kepada DRPM Dikti yang telah memberikan dana bantuan pembiayaan dalam pelaksanaan riset skema Desentralisasi PDUPT/2020. Berdasarkan Keputusan Direktur Jenderal Penguatan Riset Nomor: 83.23.3/UN37/ PPK.3.1/2020 tanggal 16 Maret 2020, tentang Penerima Pendanaan Penelitian di Perguruan Tinggi Negeri Badan Hukum tahun 2020.

\section{DAFTAR PUSTAKA}

Abun, D., Foronda, G.L., Agoot, F., Belandres, M.L. \& Magallanez, T. (2018). Measuring entrepreneurial attitude and entrepreneurial intention of ABM grade XII, International Journal of Applied Research, 4(4), 100-114.

Acs, Z.J., Szerb, L., Lafuente, E., \& Markus

G. (2019). The Global

Entrepreneurship Index. GEDI \&

RIERC, Development Institute, Washington, D.C., USA

Acs, Z.J., Qian, H., \& Stough, R.R. (2012). Regional systems of entrepreneurship: the nexus of human capital, knowledge and new firm formation. Journal of Economic Geography, 129.

Ali, A., Toping, K.J., \& Tariq, H. (2013). Entrepreneurial Attitudes among Potential Entrepreneurs. J. Commer. Soc. Sci, 5(1), 12-46.

Atiase, V.Y., Dzansi, D.Y., \& Ameh, J.K. (2020). Technology absorption capacity and firm growth in Africa. ResearGate, https://www.researchgate.net/publicat ion $/ 343041337$

Choe, K.L., Loo, S.C., \& Lau, T.C. (2013). Exploratory Study on the Relationship between Entrepreneurial Attitude and Firm's Performance. Asian Social Science, 9(4), 114-119.
Efrata, T.C. \& Maichal (2018). Role Model and Entrepreneurial Performance. Journal of Applied Management, 16(1), 27-64.

Eton, M., Mwosi, F., Mutesigensi, D., \& Ebong, C.D. (2017). The Role of Entrepreneurial Skills in the Performance of Smes in Nebbi District, Nile Region Uganda. Researchjournali's Journal of Entrepreneurship, 5(1), 2349-5383.

Fitzsimmons, J.R., \& Douglas, E.J. (2005), Entrepreneurial Attitudes and Entrepreneurial Intentions. Research Conference, Wellesley, MA. June 2005.

Fried, H.O., \& Tauer, L.W. (2015). An entrepreneur performance index. Journal of Productivity Analysis, 44(1), 69-77.

Herman, J., Vanderstraeten, J., Dejardina, M., Ramdania, D., Stam, E., \& Wittloostuijnb, Av. (2012). Ambitious Entrepreneurship: Antecedents and Consequences. Research Paper, University of Antwerp, (023), 1-30.

Johnston, M.P. (2014). Secondary Data Analysis: A Method of which the Time Has Come. Qualitative and Quantitative Methods in Libraries, (3), 619-626.

Khouroh, U., Sudiro, A., Rahayu, M. \& Indrawati, N. K. (2020). The mediation effect of entrepreneurial marketing in the relationship between environmental turbulence and dynamic capability with sustainable competitive advantage: An empirical study in Indonesian MSMEs. Management Science Letters. 10 (2020). 709-720

Martins, F.S., \& da-Cunha, A.C. (2018). Secondary Data in Research Uses and Opportunities. Iberoamerican Journal of Strategic Management, 17(3), 1-5.

Mao, C., Koidea, R., Bremb, A., \& Akenjia, L. (2020). Technology foresight for social good: Social implications of technological innovation by 2050 from a Global Expert Survey. 
Technological Forecasting \& Social Change, 153, 119914

Nehete, R.S., Narkhede, B.E., \& Mahajan, S.K. (2016). Investigation of Entrepreneurial Skills for Better Performance of Manufacturing SMEs. International Journal of Engineering Science and Technology. 3(7), 55155525.

Ngan, N.T. \& Khoi B.H. (2020). Using AIC in Model Choice about Entrepreneurial Attitude Orientatition. Internatioanl Journal of Psychosocial Rehabilitation, 24(2) 87-96.

Prasetyo, P.E., Setyadharma, A., \& Kistanti, N.R. (2020a). Social Capital: The main determinant of MSME entrepreneurship competitiveness, International Journal of Scientific \& Technology Research, 9(3), 66276637.

Prasetyo, P.E. \& Kistanti, N.R. (2020b). Human capital, institutional economics and entrepreneurship as a driver for quality \& sustainable economic growth. Entrepreneurship and Sustainability Issues, 7(4), 25752589.

Prasetyo, P.E., (2020c). Human Capital as the Main Determinant of Regional Economic Growth, International Journal of Advanced Science and Technology, 29(03), 6261-6267.

Prasetyo, P.E., \& Siswantari H. (2020d). Technology Absorption in Entrepreneurial Aspirations and Capabilities. International Journal of Innovation, Creativity and Change, 14(3), 1264-1277.

Prasetyo, P.E., \& Dzaki, F.D. (2020e). Institutional performance and new product development value chain for entrepreneurial competitive advantage. Uncertain Supply Chain Management, 8(4), 651-675.
Prasetyo, P.E. (2019a). The Reliability of Entrepreneurial Productivity as Driver of Economic Growth and Employment. International Journal of Entrepreneurship, 23(4), 1-15.

Prasetyo, P.E., \& Kistanti, NR. (2019b). The role of human capital in establishing new institutional economics and competitiveness. International Journal of Commerce and Management Research, 5(5), 64-70.

Ruzzier, M., Douglas, E.J., Ruzzier, M.K. \& Hojnik, J. (2020). International Entrepreneurial Orientation and the Intention to Internationalize. Jounal Sustainability, (12.5647), 1-20, doi:10.3390/su12145647.

Sajilan, S., Tehseen, S., \& Ojo, S.A. (2016). A Conceptual Framework of the Impact of Entrepreneurial Competencies on SME Business Performance in the Malaysian Hospitality and Tourism Industry. Rev. Integr. Bus. Econ. Res., (2), 4761.

Stam, E., Hartog, C., Stel, Av., \& Thurik, R. (2010). Ambitious entrepreneurship, high-growth firms and macroeconomic growth. EIM Business and Policy Research, 10(09), 1-32.

Stam, E., Bosma, N., Arjen, V.W., de-Jong, J., Bogaert, S., Edwards, N. \& Jaspers, F. (2012). Ambitious Entrepreneurship. Advisory Council for Science and Technology Policy, 41(1), 1-62.

Thurik, R., Hessels, J., \& Gelderen, E.M. (2008). Entrepreneurial aspirations, motivations, and their drivers. Small Bus Econ, (31), 323-339.

Vamvaka, V., Stoforos, C., Palaskas, T., \& Botsaris, C. (2020). Attitude toward entrepreneurship, perceived behavioral control, and entrepreneurial intention: dimensionality, structural relationships, and gender differences. Journal of Innovation and Entrepreneurship, 9(5), 1-26. 